\title{
DIALOGANDO SOBRE HIGIENE BUCAL COM PRÉ- ESCOLARES: PERCURSO POLÍTICO-PEDAGÓGICO PARA O PLANEJAMENTO ESTRATÉGICO DE UMA AÇÃO DE EDUCAÇÃO EM SAÚDE
}

\author{
Luiz Eduardo de Almeida1, Mirian de Souza Lucas², Patrícia Carolina Gomes², \\ Pedro Henrique Duarte de Mello², Rodrigo de Oliveira Silva ${ }^{2}$ \\ ${ }^{1}$ Docente da Faculdade de Odontologia, Universidade Federal de Juiz de Fora, Juiz de Fora- \\ MG, Brasil. \\ ${ }^{2}$ Acadêmico(a) estagiário, Faculdade de Odontologia, Universidade Federal de Juiz de Fora, \\ Juiz de Fora-MG, Brasil. \\ Email para correspondência: luiz.almeida@ufjf.edu.br
}

\begin{abstract}
Resumo
Trata-se de um relato de experiência, cujo objetivo é descrever sob estratégia narrativo-argumentativa, as experimentações político-pedagógicas atreladas ao planejamento estratégico de ações de educação em saúde bucal desenvolvidas em um ambiente escolar, destacando nesse processo analítico as significâncias vivenciadas por acadêmicos estagiários de um curso de Odontologia. Após análise detalhada, algumas inferências se destacaram: o reconhecimento do ambiente escolar como território promissor para o desenvolvimento de ações promotoras de saúde; a efetividade do instrumento "TPC" (Teorizar-Praticar-Criticar) no direcionamento dos acadêmicos estagiários no planejamento estratégico de atividades de educação em saúde bucal; a importância de se disseminar, em espaços científicos, os aprendizados advindos de experimentações práticas de estágios. Por fim, sob análise global das experimentações vivenciadas, pode-se afirmar que os estágios supervisionados emergem como abordagens extramuros fundamentais para o processo formativo dos futuros cirurgiões-dentistas, provendo um modelo de ensino pautado nas simbióticas relações entre educação ("o pensar") e trabalho ("o fazer"), ou seja, um processo construído na e para realidade, que se encerra no reconhecimento da prática como fundamento, critério e finalidade da teoria.
\end{abstract}

Palavras-chave: Higiene bucal. Educação em saúde. Creches. Estágio clínico. Planejamento estratégico. Creches.

\begin{abstract}
It is an experience report, whose objective is to describe, under a narrativeargumentative strategy, the political-pedagogical experiments linked to the strategic planning of oral health education actions in the school environment, highlighting in this analytical process the meanings experienced by intern students
\end{abstract}


of a Dentistry course. After detailed analysis, some inferences stood out: the recognition of the school environment as a promising territory for the development of health-promoting actions; the effectiveness of the "TPC" (Theorize-PracticeCriticize) instrument in directing trainee academics in the strategic planning of oral health education activities; the importance of disseminating, in scientific spaces, the learning from practical experimentation of internships. Finally, under a global analysis of the experiences experienced, it can be said that supervised internships emerge as fundamental extramural approaches to the formative process of future dentists, providing a teaching model based on the symbiotic relationships between education ("thinking") and work ("doing"), that is, a process built on and for reality, which ends in the recognition of practice as the foundation, criterion and purpose of the theory.

Keywords: Oral Hygiene. Health Education. Child Day Care Centers. Clinical Clerkship. Strategic Planning.

\section{Introdução}

Estudos contemporâneos evidenciam que o ambiente e a idade escolar se destacam frente à efetividade de ações de educação em saúde bucal (NERY, JORDÃO, FREIRE, 2019; MENEGAZ, SILVA, CASCAES, 2018; SIGAUD et al., 2017; SILVA, CARCERERI, AMANTE, 2017; PIANTINO et al., 2016; SOUZA et al., 2015).

Indo além, pode-se extrair dos trabalhos que a implementação de programas de educação para saúde bucal em escolas oferece às crianças 0 conhecimento sobre os meios efetivos para evitar as doenças bucais. A motivação é, também, um requisito indispensável para o aprendizado. É um processo pessoal, interno, que determina a direção e a intensidade do comportamento humano. O aprendizado só é realizado a partir do desencadeamento de forças motivadoras. Ressalta-se que um local ideal e apropriado para a introdução e o desenvolvimento da educação em saúde bucal é encontrado nas escolas primárias (NERY, JORDÃO, FREIRE, 2019; MENEGAZ, SILVA, CASCAES, 2018; SIGAUD et al., 2017; SILVA, CARCERERI, AMANTE, 2017; PIANTINO et al., 2016; SOUZA et al., 2015).

Adensando um pouco mais, no que tange ao processo de transmissão de informações a serem aprendidas e, principalmente, apreendidas e carreadas, a ludicidade e/ou psicomotricidade se evidenciam como instrumento de dinamização. Afinal, os métodos educativos devem ser utilizados com o intuito de tornar a aprendizagem mais agradável, atraente, significativa e estimulante, principalmente quando se trabalha com a população infantil (COTA, COSTA, 2017; SANTOS, SOUZA, SILVA, 2016; OLIVEIRA, 2014).

Complementando, Oliveira (2014), p.105 ainda destaca que 


\begin{abstract}
"As manifestações lúdicas por meio dos brinquedos trazem o ensinamento que a resolução de problemas, sobretudo bucais, pode ser divertida e é necessária. Faz o inconsciente memorizar informações sem dificuldades, além de contribuir no aprendizado de outros participantes da família. Os jogos e brinquedos, quando respeitam a faixa etária da criança, podem ser mais efetivos que os tradicionais procedimentos instrucionais utilizados na tentativa de aprendizado da prevenção".
\end{abstract}

Por fim, atravessado pela importância do desenvolvimento de ações de educação em saúde bucal em ambientes escolares, o presente estudo não apenas encontrou sua justificativa, como alicerçou o seu propósito. Assim, traz como objetivo relatar as ações de educação em saúde bucal desenvolvidas por estagiários (curso de Odontologia da Universidade Federal de Juiz de Fora / OUFJF) e vivenciadas com pré-escolares da Escola Municipal Santana Itatiaia (EM-SI), Juiz de Fora/MG. Para tal, abarcando a temática "Higiene bucal (autopercepção e autocuidado)", traz um recorte analítico das experimentações político-pedagógicas imbricadas no planejamento estratégico de todas atividades desenvolvidas.

\title{
2 Percurso metodológico
}

Em conformidade com a Resolução 510/2016 do Conselho Nacional de Saúde, por envolver seres humanos, o estudo foi aprovado e liberado, sob parecer de número 3.617.647/2019, pelo Comitê de Ética em Pesquisa da Universidade Federal de Juiz de Fora (BRASIL, 2016).

Trata-se de um estudo qualitativo, estruturado sob estratégia narrativodescritiva e moldado à técnica argumentativa. Por sua transversalidade, serão aqui referendadas as experimentações vivencias no segundo semestre de 2019, mais precisamente, de agosto a dezembro.

Quanto ao objetivo do trabalho, como já exposto, delineou-se na compreensão dos dispositivos político-pedagógicos atrelados ao planejamento estratégico de ações de educação em saúde bucal desenvolvidas por acadêmicos estagiários (Curso de Odontologia da Universidade Federal de Juiz de Fora / Estágio de Clínica Integrada em Atenção Primária) e vivenciadas com pré-escolares da Escola Municipal Santana Itatiaia (EM-SI), Juiz de Fora/MG. 
Indo além, no tocante aos investigadores, professor/tutor e acadêmicos/estagiários merece destacar a fusão de seus papéis, ora observadores, ora observados. É nesta duplicidade de funções que se consagra a observação participativa, pois nela os investigadores identificam explicitamente seus vieses, valores e interesses pessoais.

Contíguo, seguiu o processo analítico dos fatos. Neste momento, adentraram-se os elementos argumentativos do estudo, embebidos tanto pelas interpretações de seus sujeitos-autores, quanto pelo confronto junto à literatura científica. O que reforçou ainda mais o papel ativo dos pesquisadores, aqui, descobridores do significado das ações e das relações por eles vividas e percebidas.

Enfim, calcada no empoderamento de seus elementos empíricos, esta investigação não se baseou em testar hipótese, pelo contrário, galgou-se aqui uma oportunidade de ofertar a outros leitores um momento de autoanálise, afinal, muitos podem se identificar com determinados aspectos, situações e reflexões.

\section{Resultados e discussão}

Inicialmente, contextualizando a disciplina, o Estágio de Clínica Integrada em Atenção Primária, "ECl-AP", conta com duas turmas acadêmicas ( $A$ e $B$ ), sendo cada uma com carga horária semanal de 08 horas (Turma $A$ : segunda e sexta-feira/14 às 18h; Turma $B$ : quarta-feira/08 às $12 \mathrm{~h}$ e sexta-feira/14 às $18 \mathrm{~h}$ ) e dividida em cinco pontas de trabalho (Grupos I-A/B, II-A/B, III-A/B, IV-A/B e V$A / B)$ - neste estudo despontou-se o processo analítico das experimentações vivenciadas pelo Grupo III/Turma B.

Quanto a seu conteúdo pedagógico, em linhas gerais, o estágio traz em seu ementário "Capacitar o discente estagiário em planejar, de forma estratégica, ações de cunho educativo-preventivo". Assim, frente ao seu objetivo, didaticamente, a lógica do trabalho da disciplina foi, e ainda o é, sistematizada em dois períodos, "Pré-intervenção (1)" e "Intervenção (2)", Figura 1. 


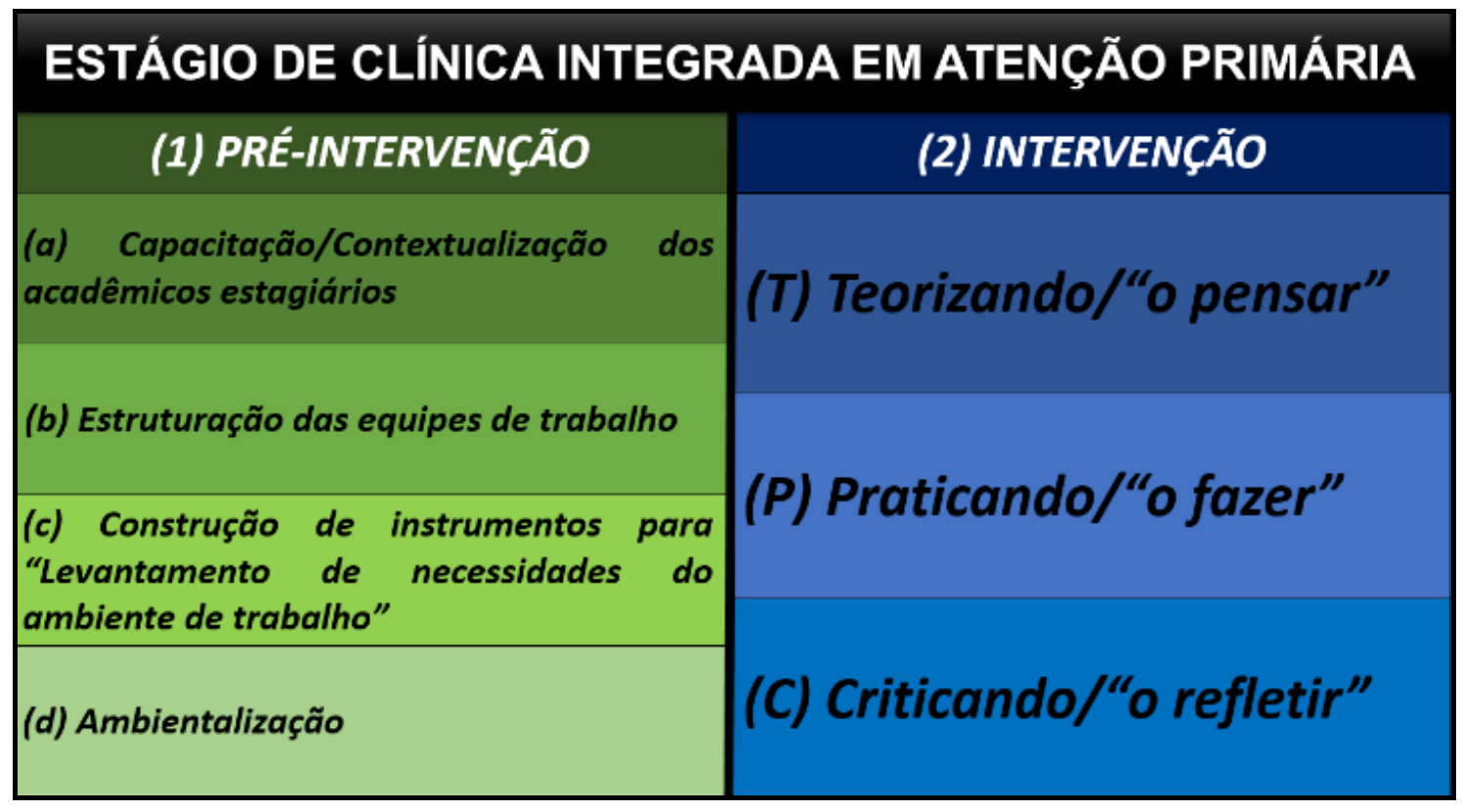

Figura 1: Dinamização do ECl-AP

Fonte: Autores, 2019

Do ciclo teorizante/(a) coube aos professores/tutores do "ECl-AP" promoverem a imersão científica dos discentes estagiários frente aos seus futuros desafios práticos (ambiente escolar, salas de espera das clínicas odontológicas da Faculdade de Odontologia e ambiente hospitalar/Hospital Universitário).

Para tal, em dois encontros (14/08 e 21/08/2019 - 08 horas), foram abordados quatro pontos de discussão: Educação em saúde; Educação em saúde em interface com a Odontologia; Educação em saúde em ambientes coletivos (ambiente escolar, salas de espera da faculdade de odontologia e ambiente hospitalar); Planejamento estratégico para o desenvolvimento de ações de educação em saúde.

Neste ínterim, merecem destaque as técnicas de mediação utilizadas, que, subsidiadas pelos ideários de diversos estudos, se deram por diferentes estratégias problematizadoras de ensino, destacando aulas expositivas, leitura crítica de artigos científicos, grupos de discussão e oficina para construção de materiais didáticos para educação em saúde (LAGE et al., 2017; REUL et al., 2016; ROCHA et al., 2016).

Ainda no dia 21/08/2019, seguindo o período "Pré-intervenção", desdobraram-se o desenvolvimento de outras duas ações programadas, a 
"Estruturação das equipes de trabalho/(b)" e a "Construção de instrumentos para 'Levantamento de necessidades do ambiente de trabalho'/(c)" destacando que neste estudo será enfocada a sistemática do ambiente escolar, mais precisamente a Escola Municipal Santana Itatiaia (EM-SI, Juiz de Fora, $M G)$.

A "EM-SI" possui aproximadamente 200 crianças matriculadas (de 4 a 6 anos), sendo elas distribuídas em 10 salas de aula, 05 por turno (matutino/vespertino). Deste modo, provendo a cobertura completa do ambiente assistido, as turmas A e B do "ECI-AP" foram divididas em 10 grupos de trabalho, cada um responsável por uma turma de pré-escolares da escola assistida. Assim, ao Grupo III/Turma B foi direcionada a sala 03 diurna (19 crianças com idade entre 4 e 6 anos).

O encontro (21/08/2019) foi encerrado com o "Levantamento de necessidades do ambiente de trabalho/(c)". Aqui exigiu-se dos grupos a construção de um roteiro de coletagem de dados (questões-chaves), cujas informações subsidiariam a estruturação das futuras intervenções educativopreventivas a serem desenvolvidas na "EM-SI".

Não obstante, após alinhamento das ideias, a fim de se prover o recolhimento dos dados de cada sala de aula, os grupos delinearam o instrumento direcionador, composto por três eixos, abaixo descrito:

- Eixo I (Análise do espaço físico - 01 membro do grupo): quantificar e qualificar o perfil dos pré-escolares (número e comportamento); acomodação das crianças (assentam em carteiras/individual ou em mesas/grupo); fazer planta baixa da sala de aula (número de mesas, carteiras, armários, ou seja, detalhar potencialidades e desafios do espaço); executar fotografias do ambiente;

- Eixo II (Entrevista da/s professora/s da sala de aula - 01 membro do grupo): aplicação de questionário semiestruturado com 13 perguntas-chaves ("1.Como a senhora classificaria a saúde bucal das crianças?"; "2.Tem alguma criança que tem reclamado de dor de dente ou até mesmo faltando a aula por causa de problemas na boca?"; "3. Em caso de necessidade de tratamento odontológico, a senhora saberia informar para os pais como buscar serviços públicos de saúde, Posto de Saúde e Faculdade de Odontologia?"; "4.Se não, a senhora gostaria de saber como se faz?"; "4.1A senhora gostaria que construíssemos um roteiro explicando o passo-a-passo de como conseguir atendimento 
odontológico na Faculdade de Odontologia?"; "5. As crianças escovam os dentes na escola?"; "5.1Se sim, quando e como acontece? Tem alguma dúvida?"; "5.2Se não, o que inviabiliza?"; "6.Todos possuem kits de higiene bucal?"; "7.Se não, a senhora gostaria que os trouxéssemos?"; "8.Há espaço adequado na sala de aula para acomodar os kits de higiene bucal?"; "8.1A senhora gostaria que construíssemos um escovário (lugar para acomodar os kits de higiene bucal)?"; "8.2Em que local da sala de aula gostaria que utilizássemos para colocar o escovário?"; "9.A senhora acha importante e necessário distribuir kits de higiene bucal para as crianças levarem para suas casas?"; "10.Gostaríamos de alcançar os pais das crianças, a senhora acha que se escrevêssemos um bilhete informativo para a família ele atingiria nosso objetivo?"; "10.1Se não, o que a senhora nos sugeriria?"; "11.No semestre anterior, outros acadêmicos estiveram em sua sala, a fim de não repetirmos a temática, a senhora se lembra 'o que' e 'como' eles trabalharam?”; 12.Daqui algumas semanas voltaremos em sua sala de aula para trabalhar com as crianças uma atividade lúdica sobre educação em saúde bucal, a senhora poderia nos direcionar/auxiliar na escolha do 'tema/problema' e, principalmente, na forma de 'como' deveremos trabalhar com as crianças?"; "13.A senhora gostaria de acrescentar mais alguma informação para nos auxiliar/direcionar?";

- Eixo III (Entrevista lúdica com os pré-escolares - 04 membros do grupo): desenvolvimento de duas dinâmicas, "Autoconhecimento" e "Desaceleração". Na primeira, após apresentação às crianças ("Olá, somos da Faculdade de Odontologia e gostaríamos de ajudar vocês a cuidarem da saúde da boca"), levantar informações direcionadoras através de 09 questões-chaves ("1.Quem aqui já foi ao dentista?"; "2.Quem tem medo de dentista?"; "3.Alguém está com algum dentinho doendo?"; "4.Quem gosta de escovar os dentes?"; “5.Quem sabe escovar os dentes?"; "6. Vocês escovam os dentes na escola?"; "7. Vocês escovam os dentes em casa?"; "8. Quem tem escova e pasta de dente?"; "9.0 que mais gostam de fazer na escola?". Para a segunda atividade, que vislumbra a despedida das crianças de forma não abrupta, levar desenhos temáticos para intervenções artísticas (colorir, dobrar, colagens, etc).

Cabe destacar que as atividades supradescritas foram programadas para acontecerem simultaneamente. Deste modo, além da otimização do tempo, todos os indivíduos (pré-escolares e professoras) a serem envolvidos nas futuras ações seriam ouvidos, sem riscos de interferências. 
Contudo, apesar de sua importância, Almeida, Pereira e Oliveira (2016) reiteram que este fundamental período de escuta é normalmente burlado pelas ações da academia, consequentemente, p. 747, "gerando um modelo de trabalho vertical-paternalista, assistencialista e, principalmente, descontextualizado do controle social".

Seguindo, o período de "Pré-Intervenção/(1)" se encerrou com a "Ambientalização/(d)", que materializou a dinamização das atividades idealizadas anteriormente, "Construção de instrumentos para 'Levantamento de necessidades do ambiente de trabalho'/(c)".

Assim, no dia 28/08/2019 as equipes de estagiários da Turma B, em turno diurno, efetivaram a visita observacional de seu cenário prático, "EM-SI" (Imagem 02). Neste processo de vistoria, intra e extraclasse, além de uma compreensão mais adensada do funcionamento do ambiente escolar, extraíram-se os anseios de aprendizagem dos assistidos. Desta sistemática, para o Grupo III/Turma B ficaram definidas as temática e forma de trabalho, respectivamente, "Higiene bucal" e "teatro interativo temático (Turma da Mônica)".

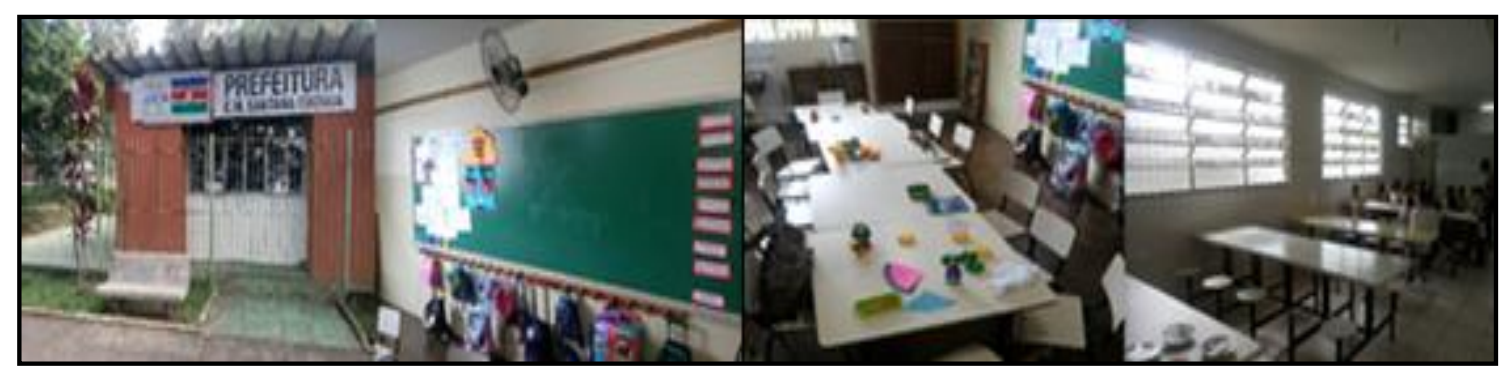

Figura 2: "Ambientalização"

Fonte: Autores, 2019

Até aqui, pode-se afirmar que este momento de escuta se alicerçou aos preceitos educacionais de Freire (2006), que defende a dialogicidade entre 0 educando e educador e a quebra da verticalidade. Em outras palavras, deslocando-se "da coisificação do ser humano (onde um ator é sujeito e o outro objeto)" em prol de uma relação em que todos possam ser sujeitos atuantes, que agem e pensam criticamente. Neste processo, aos moldes da "via de mão dupla", a academia não apenas leva informações para a comunidade (ensino), 
como traz para o cenário universitário vivências (extensão) e dados coletados e interpretados cientificamente (pesquisa).

Encerrada a "Pré-intervenção/(1)", abriu-se a "Intervenção/(2)". A partir de então, na intenção de se prover um modelo de trabalho que extrapolasse o apenas "fazer", que também alcançasse "o pensar" e o "refletir", o "ECI-AP", naturalmente extensionista, via-se afinado às idealizações e experimentações dos trabalhos de Almeida et al (2020), Almeida et al (2019), Almeida et al (2018), Almeida et al (2017) e Almeida, Pereira e Oliveira (2016), que materializaram o instrumento "TPC" (Imagem 3).

Segundo os autores, o instrumento apresentado se desenvolve em três etapas: Teorizando ("o pensar"), Praticando ("o fazer") e Criticando ("o refletir"), sendo por isso denominado TPC. Sistematicamente, as etapas se complementam, trazendo em seu bojo conceitual a relação entre planejamento estratégico com a eficácia, eficiência e efetividade de ações de educação em saúde (ALMEIDA et al, 2020; ALMEIDA et al, 2019; ALMEIDA et al, 2018; ALMEIDA et al, 2017; ALMEIDA, PEREIRA, OLIVEIRA, 2016).

Desta forma, perpassada pela sistematização do "TPC", deu-se a estruturação das ações de educação em saúde bucal a serem desenvolvidas na "EM-SI", ou seja, também sequenciadas em três etapas: "Teorizando/O pensar"; "Praticando/O fazer"; "Criticando/O refletir".

Destarte, direcionados pelo instrumento, em 04/09/2019, deu-se o ponto de partida do planejamento estratégico das demandas de trabalho do Grupo III/ Turma B, iniciando-se com a "Identificação do(s) problema(s)/1". Neste movimento, apesar da equipe estagiária saber "O quê fazer" (Desenvolver, aos preceitos da ludicidade, uma ação de educação em saúde junto a préescolares abordando a temática "Higiene bucal", a mesma se via diante de uma problemática central: "Como fazer?". 


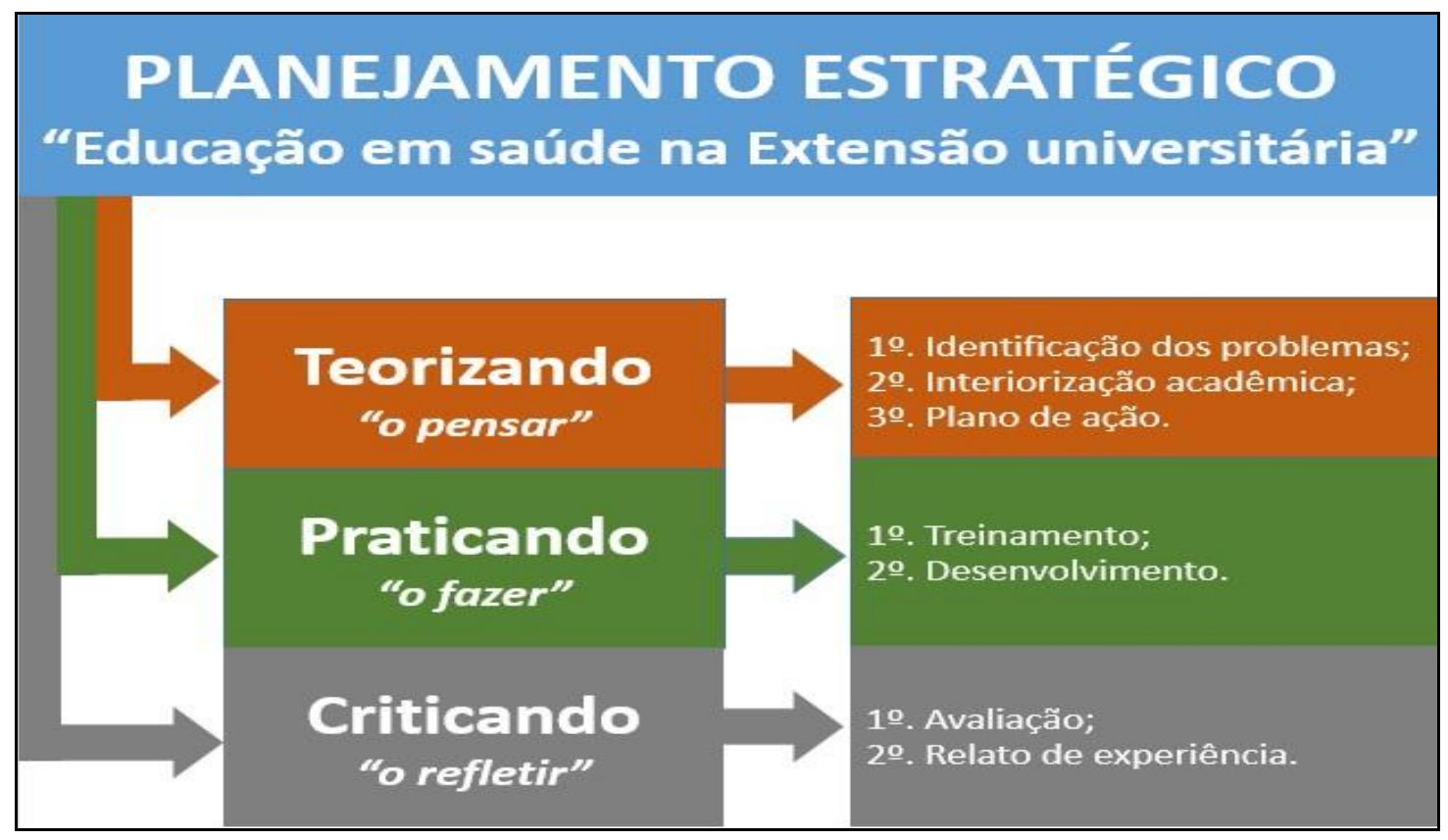

Figura 3: Instrumento "TPC"

Fonte: Almeida, Pereira e Oliveira, p.746, 2016

Defronte ao desafio, neste mesmo dia, partiu-se para a "Interiorização acadêmica/20". Daqui, solicitou-se aos estagiários o confronto dos ideários teóricos abordados durante a "Capacitação/Contextualização dos acadêmicos estagiários/(a)" com as demandas levantadas durante a "Ambientalização/(c)". Em outras palavras, instigou-se aos discentes a perceberem o seu real papel como acadêmicos, o de transformar conhecimento científico ("teoria") em instrumento ("prática") para se mudar uma realidade contextualizada.

Um processo de conscientização que se clarificou em algumas reflexões externalizadas pelos estagiários:

\footnotetext{
"as crianças já sabiam muita coisa"; "as professoras são muito interessadas, elas conhecem muito as necessidades das crianças"; "as crianças são muito agitadas, achei muito difícil controlá-las"; "eles gostam de brincar, rapidamente desconcentram e perdem o interesse em que falamos"; "a professora disse que eles adoram teatro, música, colorir e desenhar"; "as crianças não escovam os dentes na escola, muitas delas não tem o kit de higiene bucal"; "as professoras dizem não ter tempo em escovar os dentes das crianças"; "muitas crianças têm histórico ruim de saúde bucal"; "em todas as salas têm pelo menos uma criança com necessidade especial (autismo, paralisia cerebral e negligência familiar), temos que trabalhar com elas também?".
} 
Seguindo, o encontro foi encerrado com a criação do "Plano de ação/3". Atravessado pelas preconizações da metodologia "Brainstorming", a dinamização deste período retoma, através da utilização de um questionário direcionador ('O quê?', 'Quem?', 'Onde?', 'Quando?', 'Como?', 'Quanto custa?', 'Por quê?' e 'Como avaliar?') as orientações propostas pela metodologia do instrumento "TPC" (ALMEIDA et al, 2020; ALMEIDA et al, 2019; ALMEIDA et al, 2018; ALMEIDA et al, 2017; ALMEIDA, PEREIRA, OLIVEIRA, 2016).

Após amplo debate e alinhamento de ideias, esboçou-se, através da concepção de um "mapa conceitual" (Quadro 01), o "Plano de ação/30" do Grupo III/Turma B do "ECI-AP" (ROSA, GARCIA, 2017; FARIAS, FARIAS, 2016).

Quadro 1: Mapa conceitual do "Plano de ação" do Grupo III/Turma B do "ECI-AP"

\begin{tabular}{|c|c|}
\hline & "Plano de ação" - Educação em saúde em ambiente escolar - Grupo III/Turma B \\
\hline & $\begin{array}{l}\text { "O QUÊ?" } \\
\text { Desenvolver, aos preceitos da ludicidade, uma ação de educação em saúde junto a pré- } \\
\text { escolares abordando a temática "Higiene bucal (autopercepção e autocuidado)". }\end{array}$ \\
\hline & $\begin{array}{l}\text { "QUEM?" } \\
\text { Público-alvo/Expectativa: } 19 \text { crianças com idade entre } 4 \text { e } 6 \text { anos; } \\
\text { Executores: } 04 \text { estagiários. }\end{array}$ \\
\hline & $\begin{array}{c}\text { "ONDE?" } \\
\text { Sala 03/diurno da Escola Municipal Santana Itatiaia, Juiz de Fora/MG. }\end{array}$ \\
\hline & $\begin{array}{l}\text { Dia: 18/09/2019; } \\
\text { Horário de início: 08:00 horas; } \\
\text { Previsão de duracão da acão: aproximadamente } 30 \text { minutos. }\end{array}$ \\
\hline & $\begin{array}{l}\text { "COMO?" } \\
\text { Para a concepção da ação foram programadas } 06 \text { atividades, sendo elas: } \\
\text { 1. Atividade de "Aprendizado": } \\
\text { • Nome: "Teatro: Cascão e Magali e a saúde bucal"; } \\
\text { - Objetivo: desenvolver nas crianças o senso crítico da importância da higiene } \\
\text { bucal (autopercepção e autocuidado); } \\
\text { - Material: caixa de papelão encapada com TNT para fazer o cenário do teatro; } \\
\text { 03 fantoches (Cascão, Magali e Dentista) afixados em palitos de churrasco; } \\
\text { - Funções dos membros da equipe: } 01 \text { organizador (responsável pelas } \\
\text { anotações, contagem das crianças, fotografar, acomodar e estimular a } \\
\text { participação das crianças e observação global da efetividade da atividade/ } \\
\text { pontos positivos e negativos); } 01 \text { Cascão; } 01 \text { Magali; } 01 \text { cirurgiã-dentista; } \\
\text { Dinâmica: 08 passos. 10 passo: o estagiário organizador acomodará as } \\
\text { crianças em semicírculo, para otimizar a visibilidade e participação dos pré- } \\
\text { escolares junto à atividade. Ele ainda contextualizará as crianças que eles } \\
\text { ouvirão uma história que aconteceu com o "Cascão" e a "Magali" (reforçando } \\
\text { que a escolha das personagens se deu pela afinidade dos infantes com as } \\
\text { histórias da "Turma da Mônica"). Enquanto isso os demais estagiários } \\
\text { montarão o teatro. } 2^{\circ} \text { passo: a personagem "Cascão" entra em cena } \\
\text { chorando, dizendo que o dente dele está doendo, principalmente quando ele } \\
\text { come doce e bebe água gelada. } 3^{\circ} \text { passo: "Magali" se aproxima e questiona: } \\
\text { "Cascão, porque está chorando? } 4^{\circ} \text { passo: estou com dor de dente!!! } \\
\text { (Cascão). } 5^{\circ} \text { passo: Magali explica o Cascão que ele está com cárie nos }\end{array}$ \\
\hline
\end{tabular}




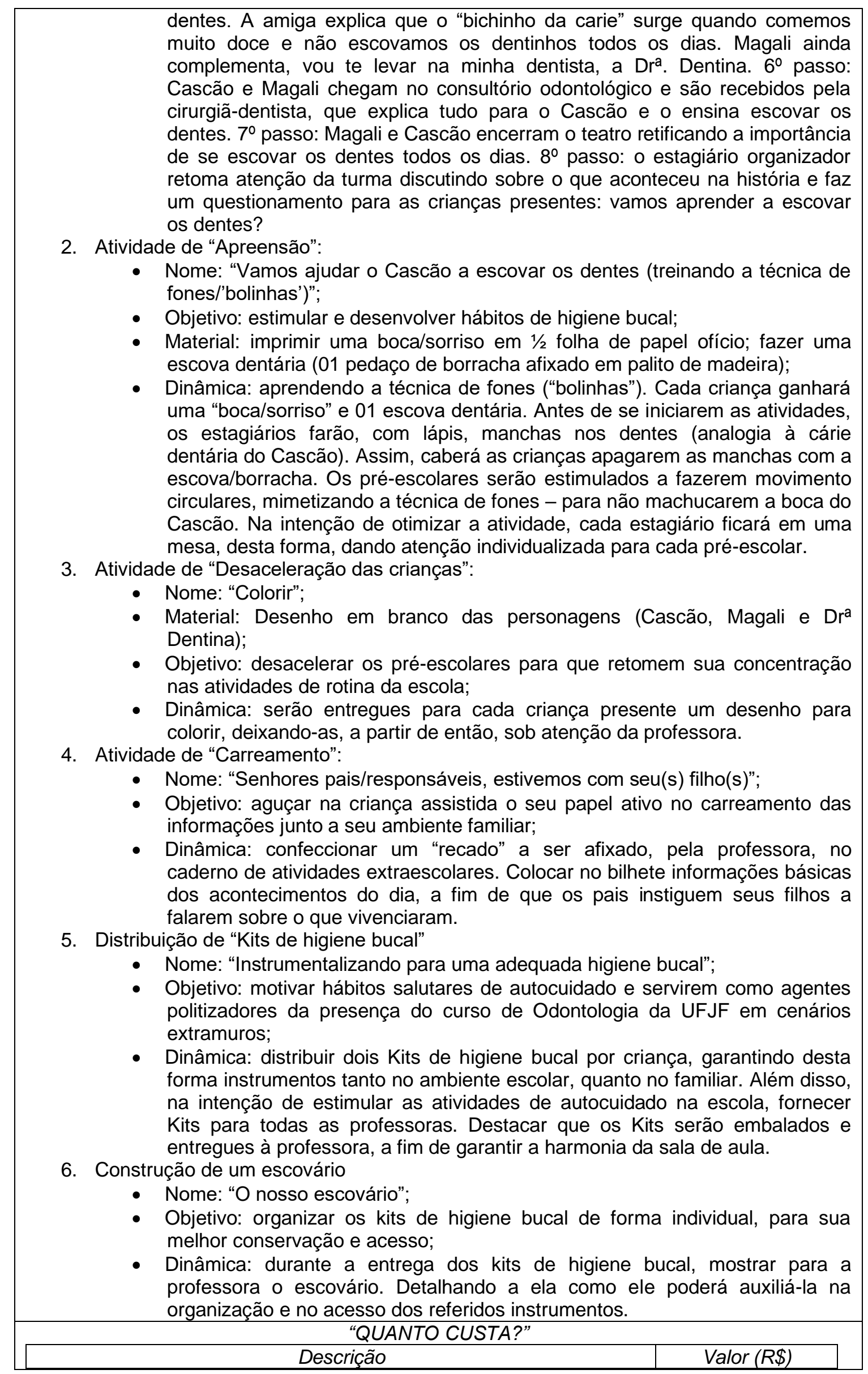




\begin{tabular}{|c|c|}
\hline Material de consumo para a construção de macromodelos & 35,40 \\
\hline Kits de higiene bucal ${ }^{*}$ & 0,00 \\
\hline TOTAL: & $35,40^{\star \star}$ \\
\hline \multicolumn{2}{|c|}{$\begin{array}{l}\text { * os kits de higiene bucal foram fornecidos pela Faculdade de Odontologia-UFJF; } \\
\text { ** os valores foram apresentados após a materialização de todos os materiais didáticos } \\
\text { previstos para a atividade. }\end{array}$} \\
\hline \multicolumn{2}{|c|}{$\begin{array}{l}\text { "A justificativa se centrou na valorização da escola como terreno fértil para o desenvolvimento } \\
\text { de atividades de educação em saúde. Além disso, a idade pré-escolar é um momento da } \\
\text { criança fundamental para a construção e consolidação de novos hábitos. }\end{array}$} \\
\hline $\begin{array}{l}\text { - Avaliação quanti-qualitativa: } \\
\text { • Quantitativa: avaliar a cobertura dos assistidos, através da r } \\
\text { crianças presentes e o número de crianças esperadas [Cobe } \\
\text { Qualitativa: avaliar o grau de adesão dos envolvidos na atividade. }\end{array}$ & $\begin{array}{l}\text { re o número de } \\
\text { P/CE)X100]; }\end{array}$ \\
\hline
\end{tabular}

Fonte: Autores, 2019

Apesar de simples, extraiu-se da etapa de construção "Plano de ação/3o" uma ferramenta indutora no engajamento dos discentes estagiários junto à solutividades de suas demandas. Uma reflexão que embasa o real papel da formação universitária, que não deve se restringir apenas ao fornecimento depositário de conhecimentos para o aluno (aprendizado), pelo contrário, deve aguçar no discente o desejo de aplicá-los (apreensão e carreamento), ou seja, ferramentas transformadoras de uma realidade social.

Além, analisando a lógica educativa utilizada, pode-se afirmar que ela celebra a efetivação do enlace ensino-serviço-comunidade (UFJF-Escola Municipal Santana Itatiaia-Pré-escolares), vista a concepção das atividades planejadas partirem do contexto social ao qual estão inseridas, ou seja, mais importante que os próprios procedimentos didáticos, é ter consciência e conhecimento do "que" e, principalmente, de "quem" serão ensinados.

Encerrado seu estágio observacional (Teorizando/"O pensar"), os estagiários partiram para a etapa "Praticando/O fazer". O ciclo prático se iniciou com o "Treinamento/10". Neste dia, 11/09/2019, os acadêmicos (Grupo III/Turma B) dinamizaram, junto aos professores/tutores, o "Plano de ação/30" previamente idealizado (Quadro 01), agora, estruturado e materializado - este processo se destacou nos ajustes e alinhamentos finais nas ações a serem desenvolvidas no ambiente escolar.

Indo além, pode-se afirmar que esta etapa teve papel fundamental na preparação da equipe de estagiários. Afinal, ela marca, de forma gradual, a mudança nas funções dos discentes, que se deslocam da condição de 
observadores/idealizadores para interventores. Almeida et al (2020) evidenciam que treinar não é eximir-se do erro, pelo contrário, no treino, através da mimetização de uma realidade, vislumbra-se capacitar uma equipe em prover estratégias secundárias para se contornar os tão frequentes e esperados obstáculos da vida real.

Assim, previamente treinados, chega 0 tão esperado "Desenvolvimento/2" do plano de ação, em 18/09/2019 (Imagem 05). Deste período, em linhas gerais, evidenciou-se o bom andamento das atividades previamente planejadas, destacando como principal ponto positivo a participação ativa dos pré-escolares assistidos. Como fragilidade, Como fragilidade, foi observada a excitação das crianças nos momentos iniciais, contudo, mais uma vez, a professora foi auxiliando a equipe de estagiários a contornar o problema.

Esta conclusão se ancorou em algumas falas dos estagiários envolvidos,

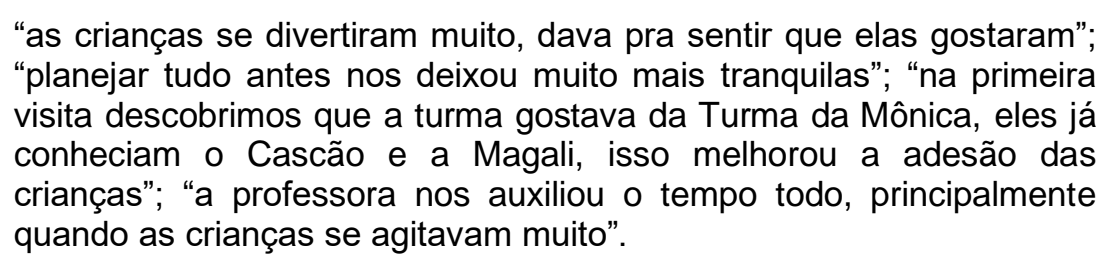

Tão logo, durante a despedida, foram deixados para os escolares Kits de higiene bucal, além de um escovário para acondicioná-los e otimizar seu acesso. Além disso, na intenção de acessar os familiares dos escolares, foi entregue à professora um bilhete para afixar no caderno de atividades extraescolares ("Carreamento").

Para encerrar o dia, após "Desenvolvimento/20" do plano de ação, os professores/tutores do "ECl-AP" se reuniram com os estagiários para se iniciar a "Avaliação/10" da ação desenvolvida (Criticando/"O pensar"). Para tal, centraram-se nos critérios quanti-qualitativos definidos durante a construção do plano de ação, "Como avaliar". Daqui extraiu-se uma cobertura de 100,00\% (19 frequentes), além do alto grau de adesão dos envolvidos durante o desenvolvimento de todas as atividades programadas. 
Adensando um pouco mais, refletindo sobre as experimentações vivenciadas pelo Grupo III/Turma B, apesar do êxito na execução do plano de ação, ficou evidente o sobrepujamento da realidade prática sobre as expectativas teóricas.

Foi justamente deste confronto entre "teoria/expectativa" e "prática/realidade" que se percebeu o "ECI-AP" como agente ativo no processo de aprendizagem dos estagiários. Afinal, os acadêmicos puderam perceber que suas funções extrapolavam o "executar". Deles foram também exigidas outras habilidades, pautadas na plasticidade do "adaptar", do "criar", do "suprimir", do "postergar", e, principalmente, do "reinventar".

Assim os discentes tiveram a oportunidade de conhecer o maior desafio de um profissional da saúde, o saber lidar com os desafios e, até mesmo, entraves da realidade. Deixando de ver estas situações como alimento para frustrações, pelo contrário, passando a encará-las como uma oportunidade de melhoramento continuado. Percepções que se alicerçam no firmado por Almeida, Pereira e Oliveira (2016), p.747 "uma equipe aprende com os acertos e se transforma com os erros".

Indo além, engendra-se que a teoria não se torna diminuta diante da realidade, pelo contrário, ela ganha forma, sentido, em suma, se justifica. Neste prisma, como dito por Rossetti (1999), p.77, "Não se deve adaptar os pacientes à ciência, deve-se adaptar a ciência às pessoas". Complementando, o mesmo autor, p.27, "Aos doutores, ensiná-los a pensar, não aplicar técnicas ou receitas".

É óbvio que não se poderia esperar, pelo menos em totalidade, a compreensão dos graduandos estagiários das reflexões supradescritas. Por isso a terceira e última etapa do "TPC", "Criticando/O refletir", se fundamentou.

Como exposto, o percurso de reflexão se iniciou com a já experienciada "Avaliação/10" e se encerrou com a construção do "Relato de Experiência/20", que integra o processo avaliativo do "ECl-AP".

De acordo com Almeida, Pereira e Oliveira (2016), p. 747, "Entre as diversas metodologias, destaca-se o "relato de experiência", ressaltando que sua construção não deve ser direcionada apenas aos acertos, ou seja, deve-se oferecer espaço também para discutir erros e fragilidades". 
Deste modo, por fim, reconhecendo o papel de divulgação e troca da publicação científica, com previsão de entrega para o dia 20/11/2019, o Grupo III/Turma B do "ECl-AP" buscou, através da materialização do presente artigo, compartilhar suas experimentações vivenciadas.

\section{Conclusão}

Frente a seu objetivo, o de descrever, sob estratégia narrativoargumentativa, as experimentações político-pedagógicas atreladas ao planejamento estratégico de ações de educação em saúde bucal desenvolvidas (por acadêmicos estagiários do curso de Odontologia da UFJF Grupo III/Turma B) em um ambiente escolar (Pré-escolares da Escola Municipal Santana Itatiaia, Juiz de Fora/MG), algumas inferências se destacaram no estudo, sendo elas:

- o reconhecimento do ambiente escolar como território promissor para o desenvolvimento de ações promotoras de saúde;

- a efetividade do instrumento "TPC" (Teorizar-Praticar-Criticar) no direcionamento dos acadêmicos estagiários no planejamento estratégico de atividades de educação em saúde bucal;

- a importância de se disseminar, em espaços científicos, os aprendizados advindos de experimentações práticas de estágios.

Por fim, sob análise global das experimentação vivenciadas pelos estagiários (Faculdade de Odontologia/UFJF - Estágio de Clínica Integrada em Atenção Primária), pode-se afirmar que cenários práticos são territórios inesgotáveis para a aplicação dos conceitos disseminados em sala de aula e para o alicerce da pesquisa, em suma, fundamentais para o processo formativo dos futuros cirurgiões-dentistas.

\section{Referências}

ALMEIDA, Luiz Eduardo de et al. análise das experimentações político-pedagógicas vivenciadas em um estágio extramuros: planejamento estratégico de ações de 
educação em saúde em salas de espera em foco. REVASF, v. 10, n. 21, p. 1-19, mai./ago., 2020.

ALMEIDA, Luiz Eduardo de et al. Análise das experimentações político-pedagógicas vivenciadas em um projeto de extensão. Interagir: pensando a extensão, v.-, n.27, p.1-10, jan./jun., 2019

ALMEIDA, Luiz Eduardo de et al. Abordagem do tabagismo em uma sala de espera: uma experiência extensionista. Extensio: R. Eletr. de Extensão, v. 15, n. 28, p. 127136, jan./abr., 2018.

ALMEIDA, Luiz Eduardo de et al. Sala de espera em extensão: doenças sexualmente transmissíveis em foco. Interfaces - Revista de Extensão da UFMG, v. 5, n. 1, p.198205, jan./jun. 2017.

ALMEIDA, Luiz Eduardo de; PEREIRA, Marília Nalon; OLIVEIRA, Valéria. Governador Valadares (MG) em Extensão: Interfaces para a Dinamização e Instrumentalização do Cenário Extensionista em um Campus Recém-Implantado. Revista Brasileira de Educação Médica, v. 40, n. 4, p. 743-750, dez., 2016.

BRASIL. Ministério da Saúde. Conselho Nacional de Saúde. Resolução n510, de 07 de abril de 2016. Brasília: Ministério da Saúde, 2016.

COTA, Ana Lídia Soares; COSTA, Bárbara Jéssica de Assunção. Atividades lúdicas como estratégia para a promoção da saúde bucal infantil. Revista Saúde e Pesquisa, v. 10, n. 2, p. 365-371, mai./ago., 2017.

FARIAS, Maria Giovanna Guedes; FARIAS, Gabriela Belmont de. Aplicação de mapas conceituais como ferramentas didático-pedagógicas na área de recursos e serviços de informação. Biblios, v.-, n. 63, p. 13-27, jan./dez., 2016.

FREIRE, Paulo. Pedagogia da Autonomia: saberes necessários à pratica educativa. São Paulo: Paz e Terra, 2006.

LAGE, Ramayana Heringer et al. Ensino e Aprendizagem em Odontologia: Análise de Sujeitos e Práticas. Rev. Bras. Educ. Med., v. 41, n. 1, p. 22-29, jan., 2017. 
MENEGAZ, Aryane Marques; SILVA, Alexandre Emídio Ribeiro; CASCAES, Andreia Morales. Educational interventions in health services and oral health: systematic review. Rev Saúde Pública, v. 52, n. -, p. 1-14, mai., 2018.

NERY, Newillames Gonçalves; JORDÃO, Lidia Moraes Ribeiro; FREIRE, Maria do Carmo Matias. School environment and oral health promotion: the National Survey of School Health (PeNSE). Rev Saúde Pública, v. 53, n. 93, p. 1-13, out., 2019.

OLIVEIRA, Julisse Carla Cunha. Atividades lúdicas na Odontopediatria: uma breve revisão da literatura. Rev. Bras. Odontol., v. 71, n. 1, p. 103-107, jan./jun. 2014

PIANTINO, Camila Belfort. et al. Propostas de ações educativas no ambiente escolar como prática de promoção da saúde. Ciência et Praxis, v. 9, n. 17, p. 49-52, jan./jun., 2016.

REUL, M.A., et al. Metodologias ativas de ensino aprendizagem na graduação em Odontologia e a contribuição da monitoria - relato de experiência. Revista da ABENO, v. 16, n. 2, p. 62-68, abr./jun., 2016.

ROCHA, J.S., et al. O uso da aprendizagem baseada em problemas na Odontologia: uma revisão crítica da literatura. Revista da ABENO, v. 16, n. 1, p. 25-38, jan./mar., 2016.

ROSA, Vinícius Medeiros da; GARCIA, Isabel Krey. Os mapas conceituais como ferramenta na análise do dinamismo das concepções sobre a natureza da ciência. Experiências em Ensino de Ciências, v. 12, n. 5, p. 1-12, jan./dez., 2017.

ROSSETTI, Hugo. Saúde para a Odontologia. São Paulo: Editora Santos, 1999.

SANTOS, C.T.; SOUZA, L.B.P.; SILVA, S.L.R. O monstro da cárie: a importância da ludicidade em atividades teórico-práticas relacionadas à saúde bucal. Espacios, v. 37, n. 33, p. 22-25, jan./dez., 2016.

SIGAUD, Cecília Helena de Siqueira et al. Promoting oral care in the preschool child: effects of a playful learning intervention. Rev Bras Enferm., v. 70, n. 3, p. 519-525, mai./jun., 2017. 
SILVA, Grasiela Garrett da; CARCERERI, Daniela Lemos; AMANTE, Cláudio José. Estudo qualitativo sobre um programa de educação em saúde bucal. Cad. Saúde Colet., v. 25, n. 1, p. 7-13, mar., 2017.

SOUZA, Larissa Moreira de et al. Saúde Bucal no Âmbito Escolar e Familiar: da Autonomia à Transformação Social. Revista Brasileira de Educação Médica, v. 39, n. 3, p. 426-432, set., 2015. 